\title{
Non-Neoplastic Chest Wall Disorder
}

National Cancer Institute

\section{Source}

National Cancer Institute. Non-Neoplastic Chest Wall Disorder. NCI Thesaurus. Code C35752.

A non-neoplastic disorder that affects the structures of the chest wall. 